\title{
UNDERSTANDING MOBILE TECHNOLOGY FOR SERVICE DELIVERY IN ACADEMIC LIBRARY
}

\author{
Tiko Iyamu, University of the Western Cape, connectvilla@gmail.com \\ Eunice Mtshali, Tshwane University of Technology, Pretoria, mtshalie@tut.ac.za
}

\begin{abstract}
The use of Mobile technologies in organisation including institution of higher education has increased significantly in recent years. In institution of higher education, the focuses have been on its use for teaching and learning. Due to the flexibility and easy accessibility, learners and educators are increasingly depending mobile technologies for their academic activities. The development of mobile technology has resulted in shifting the academic environment from traditional to mobile learning settings.

This paper focused on the possible implications of mobile devices on teaching and learning. The qualitative case study approach was employed in the study. Based on the finding from the analysis of the empirical data, a Framework was developed. The Framework could be employed to address the implications in the drive to enhance the services of academic library. Mobile learning has a lot of potential for quick and wide reaching out to the geographically wide spread of learners. The paper helps to gain a deeper understanding of the impact of mobile technology in providing services in the library of academic institutions.
\end{abstract}

Keywords: Academic Library, E-learning, Mobile technology, Mobile devices and M-learning

\section{INTRODUCTION}

Information and communication technology (ICT) continues to expand the boundaries of higher education into factors that results into anytime and anywhere experience. Mobile technology together with mobile devices presents new means for teaching and learning. Technologies which are associated with the mobile revolution and societal desires are shaping the next frontier of the knowledge age and economy [1]. There are many mobile technologies (applications and devices) which could be deployed for teaching and learning in the academic environment. They are intended to improve, wirelessly transmit learning modules and administrative data, as well as enable better and faster communication between learners and educators, between service providers such as library and users (learners and educators), and among peers.

The need to meet life's basic challenges and responsibilities has informed the invention and use of information technologies [2]. The potential of mobile devices' integration with campus wireless network can facilitate the use of e-learning tools and mobile learning to enhance tutor-to-learner and learner -to- learner communication, collaboration, reflection and critique. Learner's productivity could be enhanced by the provision of a ubiquitous computing environment. Mobile technology in organisations, particularly institution of higher education is increasing faster than it did in the last few years [3].

The changes in mobile and wireless ICTs for learning and teaching are extensive. In this study, the literature that was reviewed and explored considered the following options for e-learning and m-learning: tablet PCs [4], iPods [5], palmtop computers [6], Personal Digital Assistants (PDAs) [7], mobile phones and SMS [8,9,10,11,12], and wireless infrastructure $[13,14,15]$.

Technologies have changing at a speed of lightening, particularly in the last decade. Some educators strive to employ technology to enhance teaching and learning. Both educators and learners need to be prepared for the world of today, and not the classroom of yesterday. Mobile devices are becoming increasingly ubiquitous, many researchers and practitioners have incorporated technology into teaching and learning environment, either through studies or proof of concepts.

Some devices such as mobile phones have enjoyed extensive diffusion, whereas devices such as laptop computers have only recently reached the price point at critical mass for learners. The widespread availability of the technology is fundamental but by itself it is insufficient for effective learning environments. As mentioned by Wagner [1], 'The success of mobile learning will ultimately revolve around a mosaic of rich converged experiences. 


\section{Issues in Information Systems}

Volume 14, Issue 2, pp.71-78, 2013

The aim of this study was to develop a conceptual Framework for Mobile device, which could be used for service delivery by academic libraries. Methodology was selected to guide the study in achieve the aim.

\section{MOBILE DEVICES - LITERATURE REVIEW}

Many studies concerning formal learning has been conducted, leading to different fields such as natural sciences [19], social sciences [20] use of mobile devices for teaching and learning. Chuang et al. [21] argued that mobile learning entails the king of learning in which learners use mobile devices with digital content in order to learn and follow their studies at anytime and from any geographical location. Mobile devices help with the distribution of teaching and learning materials, enabling learners to have access to unlimited resources at their convenient.

Laouris and Eteokleous [22] portray mobile devices as an extension of the human body that are used for communication between people. Even though Laouris and Eteokleous' [23] argument sound dehumanising, many people cannot do without Mobile devices such as cellular phone. Mobile stations include devices such as laptops, cellular phones and personal digital assistants (PDAs). They are affordable and portable for easy mobility. The emergence of mobile stations ensures that computer technologies are no longer confined to desktop and office settings. Mobile stations ensure easy mobility of users and the devices. The devices have a variety of functions. For example, they can be used: 1) to record data, 2) to access information resources, and 3) to communicate with other users. As in business, Mobile devices are continually been exploited to provide enhancement for teaching and learning in in teaching and learning.

The use of mobile devices in education has increased interest from learners, educators, and parents in recent years [24, 25, 26]. Jafari et al [27] proposed a model for next generation of e-learning. The model guides the integration of different software within learning and teaching environment. Mobile computing devices could be useful tools to support learning and workplace activities [28]. Also, Mobile devices enable and support application of software tools such as email, web browser, document and data handling, security and authentication, data synchronization with other devices, personalization and collaboration agents, and e-learning content management.

According to Visser and West [29], mobile learning can also increase access in those situations where cost represents a significant barrier for learning. For learners in rural areas where environmental and infrastructural challenges hinder other learning modalities, particularly e-learning, mobile learning presents great opportunity. Mobile technology is much less costly than any other technologies such as personal computers and broadband connections that are necessary for e-learning. The ubiquity of mobile devices means that academic services can be delivered with learners existing resources such as a mobile phones and laptops. Mobile technology reduces the gap between those who can afford and the less privilege that are challenged with affordability, where access to knowledge and information is increasingly significant [30].

Mobile technology through mobile devices could be useful in increasing an individual skills and self regulative learning ability. Real time chat support communication and collaboration among learners, through which they can consume and create information both individually and collectively. Mobile technology has the ability and functionalities to enable and support face-to-face communication in the classroom. Unlike using a desktop computer with several learners, with mobile devices learners do not have to crowd around one computer [31,32].

\section{RESEARCH METHODOLOGY}

The research is an interpretive case study. The case study method was employed mainly because of the nature of the study. Yin [16] recommended case study inquiries for "how" and "why" types of research questions, where the researcher has little or no control, and the purpose is to investigate real-life contexts, phenomena, and situations .

A South African university, Capital University was used in the study. Capital University is a pseudonym name. The universities in South Africa are structured in the same way and many of them use the same or similar information systems and technologies. The Capital University is one of the largest universities in the country. It has about forty-five thousand students on its yearly registration. The lager an environment, the more complex it becomes. The university was selected because of its complexity. It encompasses more factors than a smaller (in 
size) university. Therefore if the challenges can be addressed in Capital University, the probability is high that the same challenges would be easier to address in smaller (in size) universities.

The semi-structure interview approach was employed in the data collection, primarily because it allows a twoway interaction between the interviewer and interviewees [17]. A total number of 11 interviews were conducted. On the $11^{\text {th }}$ interview, a point of saturation was reached, meaning there was no new information that was forthcoming. The interviewees constituted of students, academics and employees of the library of the Capital University.

The intepretivism approach was adopted because of the nature of the study that sought to understand the implication of mobile devices on teaching and learning. According to Doolin and McLeod [18], the intepretivism approach is grounded in empirical interpretation, reflective approach, and interpretation of findings. Interpretivism approach relies on naturalistic, methods such as interviewing, observation and analysis of existing texts. These methods ensure an adequate dialog between the researcher and those with whom they interact in order to collaboratively construct a meaningful reality.

The research questions were: (i) how are the services offered by the University Library currently provided through information systems and technology? (ii) what are the factors which could influence the adoption of mobile technology for library services?

\section{DATA ANALYSIS AND DISCUSSION}

Data was collected based on the objectives and questions. The data was rigorously analysed using the interpretivism technique. The analysis was carried out in accordance to the research questions as presented in the Introduction section, and repeated: (i) how are the services offered by the University Library currently provided through information systems and technology? (ii) what are the factors which could influence the adoption of mobile technology for library services?

From the analysis, there were some findings. The findings were interpreted to make sense of them in the context of Mobile technology adoption and in the context of an academic library. The sense making from the findings led to the development of a Framework. The primary aim of the Framework is to guide the adoption of Mobile technology with the intention to enhance the services which the library offers.

The Framework outlines the factors that are significant and essential to the adoption of Mobile technology. Without those factors, it would be impossible or difficult to adopt Mobile technology in the library. If adopted without taking full consideration of the factors, Mobile technology will be challenged in terms of achieving its objectives.

\section{How are the services offered by the University Library currently provided through information systems and technology?}

The study examined the current systems by interacting with the users of the systems and technology. The examination was carried out through observation and document analysis.

The study revealed that systems and technology was enabling and at the same time constraining to the users. For example, the technology infrastructure that the library had was either obsolete or outdated. As a result, it did not allow compatibility with the emerging technology devices, thereby constraining connectivity and accessibility to the services. Lack of accessibility and technology constrains and limits the stakeholders' mobility.

The library is not responding to the technological innovation of emerging technologies. Lack of interest and knowledge on new technologies by some of the stakeholders who are reluctant to use the technology could hinder them from using the technology. Current technology obsolesce in the library slows down the process of delivering services and hinders the use of technology innovation.

Capital University is lagging behind modern and evolving technological innovation. It still uses the local area network (LAN). The library is not responding to the emerging technologies that stakeholders are familiar with 
and currently use to access service through mobile technology from other institutions such as the banking industry. The level of innovation is below expectation at Capital university library.

Lack of interest and knowledge from some of the stakeholders who are not technologically inclined, they prefer the traditional way of accessing library services for accessing the library services manually by being physically present at the library premises. They lack the knowledge of technological know-how.

Lack of communication and poor attendance of training could impact on the use of mobile technology. The library communication between employees and stakeholders is too limited.

\section{What are the factors that could influence the adoption of mobile technology for library services?}

The analyses revealed that the factors that could influence the adoption of Mobile technology for library services are both technical and non-technical. The technical factors are mainly technology and its compatibility. While the non-technical factors are primarily human and process related

The stakeholders (users of the library services) have different ways of accessing library services. Some of them access the services manually and others prefer to explore the information systems and technology which are deployed by the library to provide its services. Some of the library stakeholders who prefer to use information systems and technology deployed in the library struggle to do so because of lack training and understanding on how to use the systems.

The scarcity of resources such as computers (PC), space, human resource (limited librarians) affects the quality of service that the library offers to its stakeholders particularly the turnaround time. The current system requires physical presence for accessibility and connectivity. There is no flexibility and mobility is limited.

Some of the library stakeholders are technologically inclined and the thought and notion of the use of emerging technologies, some of them use mobile technology for banking, registration at Capital University at the beginning of each academic year.

Organisational structure and governance of the Capital University library are not compatible with the culture and tradition of Capital University and the community that the library serves. Communication and information sharing in the library is too limited to fulfil the university's goals and objectives. This attributes to time consuming, physical barrier and constrains.

The study helps to understand and establish the importance of processes in the adoption of mobile technology in libraries. The analysis examined the factors that could influence and impact on the use of mobile technology in accessing library services.

It was revealed in the analyses that it is important that roles and responsibilities be clearly defined and understood by stakeholders and library employees. The Library requires a technology strategy in order to respond in accordance with the emerging technologies in order to meet the changing needs of library stakeholders and the changing technology. The obsolesce of technologies in the library is due to lack of a technology strategy. The lack of a technology strategy has hampered some of the services which the library offers to its users and will thus hinder new innovations.

\section{CONCEPTUALISED FRAMEWORK FOR MOBILE DEVICE-BASED SERVICE DELIVERY IN ACADEMIC LIBRARY}

This section provides answer to the question: How can a Framework be used for the adoption of mobile technology to enhance the Capital University Library services? Based on the analysis, and the findings from the case study a Framework was developed. As depicted in Figure 1, the Framework is aimed to guide and facilitate the adoption of Mobile Technology to enhance the library services in the Capital university library. As illustrated in the Figure 1, the services which are provided by the library will be better enabled by technology (Mobile) which allows for mobility (anywhere), flexibility and available at all times. The deployed technology requires management to review its services otherwise the purpose would be defeated. Manageability involves critical factors such as governance, process and people. Both the technology and management efforts and factors ensure the communicative scheme, which facilitates communication and information sharing in the services provided by the library of the university $(\mathrm{CU})$. 
The discussion that follows should be read in conjunction with Figure 1 to gain a better understanding of how some factors could influence and impact the adoption of Mobile Technology in the environment of Capital University.

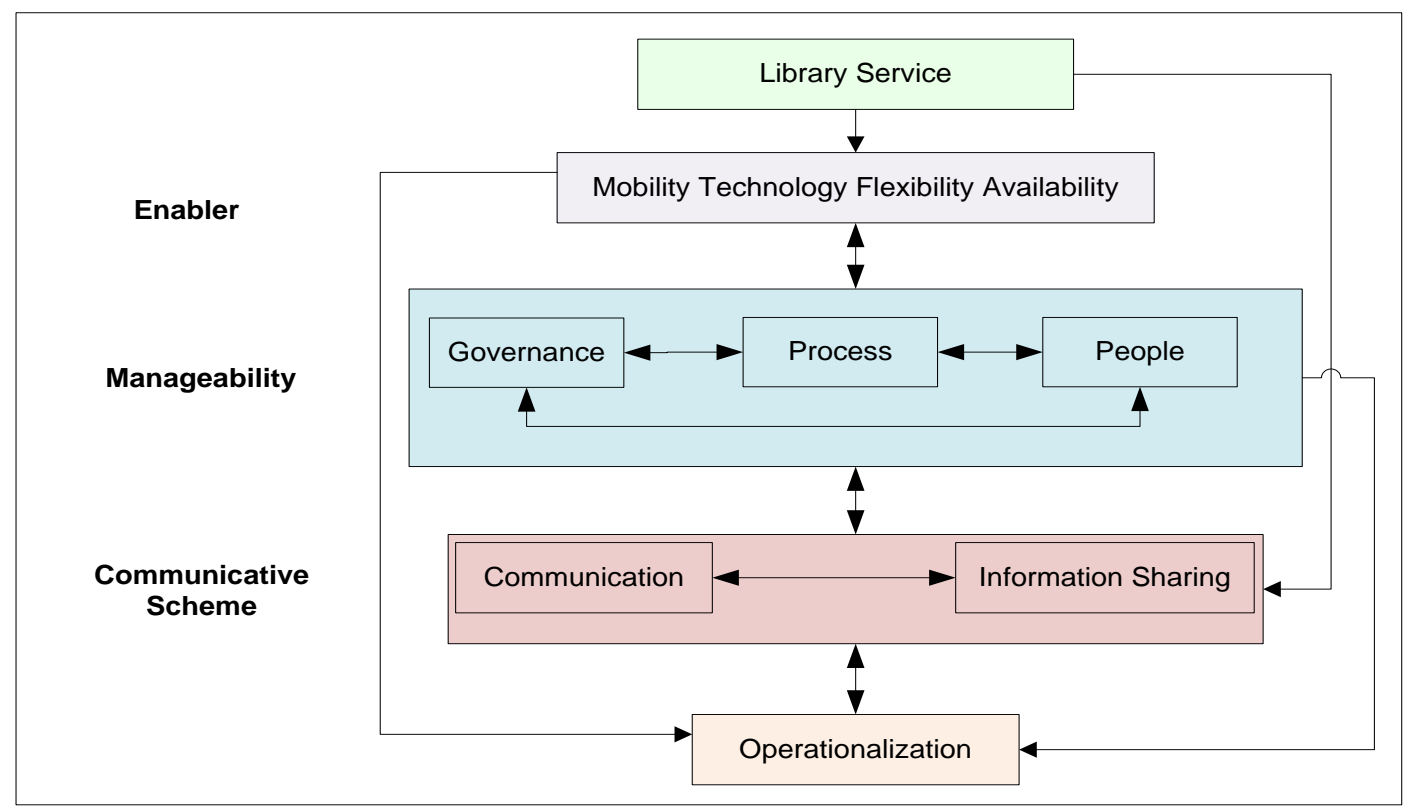

Figure 1: Framework for mobile technology

\section{i. Library services}

The Library of Capital University is the custodian of books, journal articles (printed and online), and other material such as CD (for visual and audio) for study purposes.

The effectiveness and efficiency of the operationalization of the library's activities is essential and significant to the university's (CU) academic performance. The library is a focal point for teaching, learning and research. It is expected to provide information and resources to students and academics of the university, for their academic obligations and responsibilities such as teaching, assignments, projects and research.

The adoption of Mobile technology is intended to enhance the library's services. This is to provide access to information and resource material (such as e-book) online, at anytime and from anywhere. The technology is as good as its manageability to enhance the intended services. Also critical is the communicative scheme that must contribute to improved services.

ii. Technology

The goals and objectives that inform and drive the services of the University library require enabling and management. As a result, the technology that is adopted to enable the services is critical. As revealed in the analysis, the current information systems deployed in the library are challenged with fulfilling and achieving the goals and objectives of users of Capital University.

The adoption of Mobile technology is intended to create and support information systems that are integrated with people and processes in order to provide service in an effective and efficient manner. Mobile technology is adopted for employees in the library to communicate with each other, to avail the services they provide online, and for the users to access the services in a flexible manner. The adoption of Mobile technology is intended to modernise and improve the services the University's library provides.

The management of the adopted technology is very important. The manageability of the adoption of Mobile technology includes critical factors such as governance, process and people. The governance defines principles, 


\section{Issues in Information Systems}

Volume 14, Issue 2, pp.71-78, 2013

standards and policies within which and how the Mobile technology is used to carry out the services of the library at greater height. The process factor ensures the procedural approach through which and how stakeholders (employers and users) carry out their roles and responsibilities in terms of the services the library provides. Another important factor that requires attention and management is people. People (employers and users) use and interpret technology in their own way to make a difference.

\section{iii. Governance}

Governance defines standards, principles and policies. It is driven by the organisational (library) requirements, goals and objectives pursued at the time. As such, it is not static, it requires continued review. The governance is used to guide the selection, deployment and use of the technology. It constitutes and at the same time provides a guide to both technical and non-technical factors.

The adoption of the Mobile technology requires governance. This includes the standard of the Mobile technology, the principles on how the technology is deployed and the policy on usage. The governance also guides the manageability such as upgrading of the technology.

The roles and responsibilities of the library need to be well defined for the understanding of the employees and users. The governance defines the roles and responsibilities within the timeframe. This is based on the tasks and activities that are involved in the adoption of Mobile technology in the organisation (library).

Even though governance is intended to manage the resources such as the technology, it is not necessary so in reality. It governance enables and constrain the activities for its formulation. Hence manageability through governance is critical as it is formulated by people and through process.

iv. Process and People

It is impossible or difficult to separate process and people in a social context. A social context consists and constitutes people, artefacts and events within a legitimised entity. Process is a guideline for the events and activities that people are involved in or carry out. People exist within process, and process is formulated by people.

Process is action of taking something established, usually a routine set of procedure to convert it from one form to another. Process involves steps and decision in the way work is accomplished and may involve a sequence of events. The library uses technology to carry out processes. It is significant for the library to have a standard process and to choose technologies within governance and skilled people who understand rules and regulations to be able to deliver library services to stakeholders. People need to be technologically inclined to use different mobile devices that is used to access library services.

Irrespective of the potential of the technology, people decide on how to make a difference. The use of technology is conscious, and can be of practical unconsciousness. Hence the consciousness and training of employees and users of the library services is significantly critical.

\section{v. Communication and Information Sharing}

Communication and information sharing are constituted in the concept of the communicative scheme. The communicative scheme facilitates interactions and information flow between individuals and groups for the same or similar purposes in a network.

Communication is passing of information and understanding form one person to another at the same level or different level. It facilitates the achievement of organisational goals. It is carried out through verbal and nonverbal channels. Communication in the library is carried out within the library (between employees and stakeholders) and in some cases between libraries. Effective communication is essential in an organisation because it creates mutual understanding between people. Library is geared towards serving the stakeholders of the library in order to achieve desired results. Good communication gives a sense of direction and serves as a guide.

Information sharing is vital in an organisation because it would help employees to share with each other their responsibilities. This will help them to provide a better service if they know who is doing what in the organisation. They can even share with each other how to provide certain services. This will help their colleagues to provide those services when they are not available to help their clients with their queries. 
Information sharing is done through communication, once they understand the processes and the technology on how to deliver services to their stakeholders; this will lead to the operationalization of the new technology.

The communicative scheme is enabled by Mobile technology, to ensure that communication and information are delivered in real-time, virtualised and available through various devices at all times. The adoption of Mobile technology helps to communicate and share information intensively and extensively without time limitation and geographical barriers and information sharing is enforced.

\section{vi. Operationalization}

Operationalization entails the applicability and use of the library services by the employees and consumers (users). Based on the analysis, the adoption of Mobile technology would enhance the effectiveness and efficiency of the library's activities.

Mobile technology would allow library stakeholders to access library services anywhere and anytime though any mobile device as long as they are connected to the Internet. The services would be accessed through the library website. Stakeholders will use their university identity number for authentication, so that they could get access to the electronic resources of the library. Once they have authenticated themselves, they will be able to check for books on the library catalogue, access electronic journal articles through different databases. The stakeholders would be able to check for books, reserve and renew the books online. They would only come to the library to collect the books.

\section{CONCLUSIONS}

Mobile technology transcends time restriction, spatial limitations and free library stakeholders from restriction related to opening and closing hours of the library. Stakeholders would be able to enjoy library services without having to be physically present at the library premises.

The Framework provides a guide through which Mobile technology could be deployed, monitored and managed in organisations including academic library. The results of the study intended to create awareness for the university community, thus, helping them to make informed decisions for the adoption and management of Mobile technology.

Another benefit of the study is the publication of the findings that add to the literature, thereby contributing to the body of knowledge from the perspectives of knowledge and information management.

\section{REFERENCES}

[1]. Wagner, E. D. (2005). Enabling mobile learning. EDUCAUSE Review, Vol. 40,No. 3, pp: 40-53

[2]. Ademodi, D. T. and Adepoju, E.O. (2009). Computer skill among librarians in academic libraries in Ondo and Ekiti States, Nigeria. Library Philosophy and Practice 2009. Retrieved from http://unllib.unl.edu/LPP/ademodi-adepoju.htm

[3]. Castells, M., Fernandez-Ardevo,1 M., Linchuan Qiu, J. and Sey, A. (2007). Mobile Communication and Society: A Global Perspective. Cambridge, MA: MIT Press.

[4]. Corlett, D. and Sharples, M. (2004). Tablet technology for informal collaboration in higher education. Third annual Mlearn international conference on Learning Anytime, Everywhere, Rome, 5-6 July, 2004.

[5]. Perlman, D. (2005). Drexel gives iPod photos to education grads. Retrieved from http://www.dailypennsylvanian.com/vnews/display.v/ART/2005/03/04/42283c0b2ed6

[6]. Savill-Smith, C. and Kent, P. 2003. The use of palmtop computers for learning: A review of the literature. London, UK: Learning and Skills Development Agency.

[7]. Singh, G., Denoue, L. \& Das, A. 2004. Collaborative note taking. Proceedings of the 2nd IEEE workshop on wireless and mobile technologies in education (WMTE '04), pp. 163-167, JungLi, Taiwan: IEEE Computer Society. 


\section{Issues in Information Systems}

Volume 14, Issue 2, pp.71-78, 2013

[8]. Cochrane, T. 2005. Mobilising learning: A primer for utilising wireless palm devices to facilitate a collaborative learning environment. Proceedings of ASCILITE

[9]. Cheung, S. 2004. Using mobile phone messaging as a response medium in classroom experiments. Social science research network

[10]. Faulkner, S. 2004. Have you got my number? Campus Review, 17, August 18-24

[11]. Gonzales, G., Ilttelson, J., \& Krebs, A. 2004. Mobile education: On campus and in the community. Proceedings from EDUCAUSE, Denver, CO

[12]. Hennessy, S. 2000. Graphing investigations using portable (palmtop) technology. Journal of Computer Assisted Learning, 16, 243-258

[13]. Sotillo, S.M. 2003. Pedagogical advantages of ubiquitous computing in a wireless environment. The Technology Source.

[14]. Falk, H. 2003. Electronic campus. The Electronic Library, Vol. 21, No. 1, pp. 63-66

[15]. Lu, J., Chun-Sheng, Y., Chang, L. and Yao, J. E. (2003). Technology acceptance model for wireless internet. Internet Research: Electronic Networking Applications and Policy, Vol. 13, No. 13, pp. 206-222

[16]. Yin, R. K. (2009) Case study research: design and methods, 4th ed., Sage, Los Angeles.

[17]. Babbie, E. \& Mouton, J. (2001) The practice of social research, Oxford University Press, Cape Town.

[18]. Doolin, B., and McLeod, L. (2005), "Towards critical interpretivism in IS research," in: Handbook of Critical Information Systems Research: Theory and Application, D. Howcroft and E.M. Trauth (eds.), Edward Elgar, Cheltenham, 2005, pp. 244-271.

[19]. Lai, C.-H., Yang, J.-C., Chen, F.-C., Ho, C.-W. \& Chan, T.-W. (2007). Affordances of mobile technologies for experiential learning: The interplay of technology and pedagogical practices. Journal of Computer Assisted Learning, 23, 326-337

[20]. Fischer, G. \& Konomi, S. (2007) Innovative socio-technical environments in support of distributed intelligence and lifelong learning. Journal of Computer Assisted Learning, 23(4), 338-350

[21]. Chuang, T., Nakatani, K. and Zhou, D. (2009), “An Exploratory Study of the Extent of Information Technology Adoption in SMEs: An Application of Upper Echelon Theory”, Journal of Enterprise Information Management, Vol.22, No.1, pp.183-196.

[22]. Laoris, Y. and Eteokleous, N. (2005). We need an Educationally Relevant Definition of Mobile Learning. Proceedings of the 4th World Conference on M-learning Library Association Information Services Group. 1999. Guidelines for reference and information services in public libraries. London: Library Association publishing.

[23]. Alexander, B. (2004). Going nomadic: Mobile learning in higher education. EDUCAUSE Review, Vol. 35, No. 5, pp. 29-35

[24]. Alexander, B. (2006). Web 2.0: A new wave of innovation for teaching and learning? EDUCAUSE Review, Vol. 41, No. 2, pp. 32-44.

[25]. Attewell, J. (2005). From research and development to mobile learning: Tools for education and training providers and their learners. Proceedings of MLearn

[26]. Bryant, T. (2006). Social software in academia. EDUCAUSE Quarterly, Vol. 29, No. 2, pp. 61-64

[27].Jafari, A., Mcgee, P. and Carmean, C. 2006. Managing courses, defining learning: What faculty, students, and administrators want. Educause review, July/August, 50-70.

[28]. Soloway, E., Norris, C., Blumenfeld, P., Fishman, B.J. and Marx, R. (2001). Hand-held devices are ready at hand. Communications of the ACM, Vol. 44, No. 6, pp. 15-20

[29]. Visser, L. and West, P. (2005). The promise of m-learning for distance education in South Africa and other developing nations. In Y. L. Visser, L. Visser, M. Simonson, \& R. Amirault (Eds.), Trends and issues in distance education: International perspectives, pp. 117-129, Greenwich, CT.: Information Age Publishing.

[30]. Van Weert, T. (2005). Lifelong learning in knowledge society: Implications for education. In T. J. van Weert (Ed.), Education and the knowledge society: Information technology supporting human development, pp. 15-25, Boston: Kluwer Academic Publishing.

[31]. Crowe, A. R. (2007). Learning to teach with mobile technology: A teacher educator's journey. In M. van't Hooft \& K. Swan (Eds.), Ubiquitous computing in education, pp. 127-144, Mahwah, New Jersey: Lawrence Erlbaum Associates.

[32]. Pea, R. \& Maldonado, H. (2006). WILD for learning: Interacting through new computing devices anytime, anywhere. In R. K. Sawyer (Ed.), The Cambridge handbook of the learning sciences, pp. 427441, Cambridge: Cambridge University Press. 